\title{
纳米微粒 $\mathrm{SnO}_{2}$ 的光限幅特性 ${ }^{*}$
}

\author{
余保龙 \\ (中国科学院上海光学精密机械研究所, 上海 201800) \\ 张桂兰汤国庆 苏海涛 $* *$ 陈文驹 \\ (南开大学现代光学研究所, 天津 300071)
}

\section{关钺词纳米微粒 $\mathrm{SnO}_{2}$ 光限幅效应}

随着高灵敏块响应光电探测器的广泛应用, 迫切需要研制一些光限幅器来保护这些精密 仪器. 光限幅器的工作原理是基于材料的非线性光学特性, 因而选择合适材料并研究它的非 线性光学响应是非线性光学中非常重要的课题. 纳米微粒有相对大的比表面积, 在微粒表面存 在大量原子空位或缺陷, 形成表面受陷态 (trapped states) ${ }^{[1]}$. 在外界激光作用下, 这些表面受 陷态成为有效光生载流子的无辐射途径, 导致大的热致折射率变化, 形成瞬态热透镜. 这个 热透镜使信号光束出现扩散或会聚, 通过选择样品相对位置, 从而实现光束限幅效应. 近年 来, 利用非线性光学原理的光限幅效应研究已有一些报道 ${ }^{[2.31}$, 大多采用的是有机非线性材料和 体相半导体材料, 但存在着材料稳定性差及限制效果不太理想等局限性. 利用单光束 $Z$ - 扫 描技术, 本文进行了表面修饰的 $\mathrm{SnO}_{2}$ 纳米微粒热致折射率 $n_{2}$ 测量和它的光限幅特性研究.

\section{1 样品制备}

$\mathrm{SnO}_{2}$ 纳米微粒样品是采用胶体化学方法制备的. 取浓度为 $0.1 \mathrm{~mol} / \mathrm{L}$ 的 $\mathrm{SnCl}_{4}$ 水溶液 $10 \mathrm{~mL}$ 稀释到 $50 \mathrm{~mL}$, 加人 $100 \mathrm{~mL}$ 溶有一定量的十二烷基苯磺酸钠 (DBS) 的二甲苯溶液中, 搅拌 $0.5 \mathrm{~h}$ 后, 滴加 $\mathrm{NaOH}$ 水溶液 $20 \mathrm{~mL}$, 继续摚拌一段时间后静置分层, 上层有机液回流 $0.5 \mathrm{~h}$, 除去其中水分, 用蒸馏水清洗有机相去掉杂质, 蒸馏得表面包覆有 $\mathrm{DBS}$ 的 $\mathrm{SnO}_{2}$ 纳米微 粒有机溶胶. 经透射电镜和小角度 $\mathrm{X}$ 射线衍射实验证实, 此法制备的 $\mathrm{SnO}_{2}$ 纳米微粒呈球状 分布, 分散性较好, 粒径约为 $5 \mathrm{~nm}$.

\section{2 实验结果与讨论}

表面修饰 $\mathrm{SnO}_{2}$ 纳米微粒有机溶胶热致非线性折射率 $n_{2}$ 测量是采用单光束 $Z$ - 扫描技术 进行的, 该法具有设备简单、光路调节容易、合理配置光路能获得多种信息等优点 ${ }^{149}$. 图 1 所 示实验装置是在 Sheik Bahae 等人 ${ }^{[4]}$ 的 $Z$ - 扫描基础上作适当改进而成的. 实验所用光源为 $\mathrm{Ar}^{+}$

1995-10-05 收稿, 1996-01-29 收修改稿

*国家科委 “粼登”计划资助项目

** 现在地址: 河南大学物理系, 开封 475001 


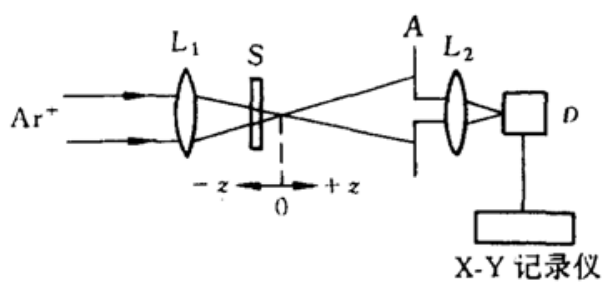

图 1 Z- 扫描实验装置 $D$ 为探测器, $L$ 为会聚透镜

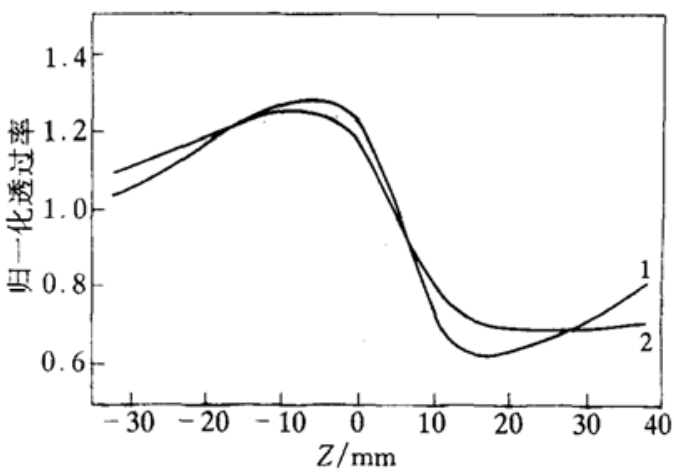

图 2

1. $P_{\mathrm{in}}=2.80 \mathrm{~mW}, \lambda=448.0 \mathrm{~nm}, S=0.41$;

2. $P_{\mathrm{ta}}=2.34 \mathrm{~mW}, \lambda=514.5 \mathrm{~nm}, S=0.53$

激光器, 工作波长分别为 514.5 和 $488.0 \mathrm{~nm}$. 图 2 为利用上述装置测得的归一化透过率曲 线. 从上述测量结果明显可以得到下列结论: (1) 曲线形状先峰后谷, 表明 $\mathrm{SnO}_{2}$ 纳米微粒具 有负透镜效应 (negative lenslike), 即热致折射率 $n_{2}$ 为负值. (2) 曲线峰谷值大小对称, 表明 不存在非线性吸收 (饱和吸收或多光子吸收).

已知因热透镜效应产生的非线性折射率 $n_{2}$ 与总折射率 $n$ 之间的关系为 $n=n_{0}+n_{2} I_{0}$, 其中 $n_{0}$ 为样品的线性折射率, $I_{0}=2 P / \pi \omega_{0}^{2}$ 为焦点处激光功率密度, $P$ 为人射激光平均功率, $\omega_{0}$ 为焦 点处激光束腰半径, 对 $\lambda=514.5 \mathrm{~nm}, \omega_{0}=33 \mu \mathrm{m} ; \lambda=488.0 \mathrm{~nm}, \omega_{0}=32 \mu \mathrm{m}$. 因光束衍射长度 $Z_{0}=\pi \omega_{0}^{2} / \lambda \gg L$ (本实验中样品池厚度 $L$ 为 $2 \mathrm{~mm}$ ), 于是样品可作为薄透镜近似. 利用公式 (1) 可得到光轴上相移 $\Delta \Phi_{0}$.

$$
\Delta T_{\mathrm{pv}}=f\left|\Delta \Phi_{0}\right|, \text { 其中 }\left|\Delta \Phi_{0}\right| \leqslant \pi,
$$

式中 $\Delta T_{\mathrm{pv}}$ 为归一化透过率峰 - 谷差值, $f=0.406 \times(1-S)^{0.25}, S$ 为光栏 $A$ 的线性透过率. 根 据 $\Delta \Phi_{0}$ 与 $n_{2}$ 关系 $^{[4]}$

$$
\left|\Delta \Phi_{0}\right|=-\frac{2 \pi}{\lambda} \Delta n L_{\text {eff }}=-\frac{2 \pi}{\lambda} n_{2} I_{0} L_{\text {eff }}
$$

表 1 表面修饰 $\mathrm{SnO}_{2}$ 纳米微粒热致折射率 $n_{2}$ 测量

\begin{tabular}{lcc}
\hline & \multicolumn{2}{c}{ 波长 $/ \mathrm{nm}$} \\
\cline { 2 - 3 } & \multicolumn{1}{c}{514.5} & 488.0 \\
\hline$\omega_{0} / \mathrm{mm}$ & $\sim 33$ & $\sim 32$ \\
$P / \mathrm{mW}$ & 2.34 & 2.40 \\
$I_{0} / \mathrm{W} \cdot \mathrm{cm}^{-2}$ & 136.9 & 149.0 \\
$\alpha / \mathrm{cm}^{-1}$ & 2.0 & 3.2 \\
$S$ & 0.53 & 0.41 \\
$\Delta n$ & $-(8.57 \pm 0.1) \times 10^{-5}$ & $-(1.01 \pm 0.1) \times 10^{-4}$ \\
$n_{2} / \mathrm{cm}^{2} \cdot \mathrm{W}^{-1}$ & $-(6.26 \pm 0.1) \times 10^{-7}$ & $-(6.7 \pm 0.1) \times 10^{-7}$ \\
\hline
\end{tabular}

波长减小, $\left|n_{2}\right|$ 有增大趋势.
其中 $L_{e f f}=\left(1-\mathrm{e}^{-\alpha L}\right) / \alpha$ 为样品有效厚度, $\alpha$ 为样品的线性吸收系数. 利用图 2 及 (1) 式和 (2) 式计算得到结果如表 1 所 示, 实验误差为 $\pm 10 \%$.

表 1 表明表面化学修饰 $\mathrm{SnO}_{2}$ 纳米微 粒在可见区有较大热致折射率产生, 而 体相 $\mathrm{SnO}_{2}$ 材料 (单晶或多晶体) 在可见 区线性吸收系数等于零间, 无热透镜效应 产生. 由表 1 还可以看出, 随人射激光 
光限幅特性实验装置同图 1, 为了获得最佳限制效果, 将样品置于图 2 中归一化透过率谷 位置上, 测量结果如图 3 所示. 为了比较 $\mathrm{SnO}_{2}$ 纳米微粒对不同波长激光的限制效果, 我们分 别测定了 $\mathrm{Ar}^{+}$激光器 514.5 和 $488.0 \mathrm{~nm}$ 两种波长限幅特性曲线. 它们显然不同于体相单晶材 料的光限幅特性 ${ }^{[3]}$. 当人射光功率超过一定阈值时, 输出光强减小而不是保持一恒定值, 即当 人射光强超过一定阈值时, 光限幅器将关闭, 此特性可用来保护高灵敏光电探测器. 由上述 特性曲线, 我们很容易得到上述两种波长限幅阈值强度分别为 $321 \mathrm{~W} / \mathrm{cm}^{2}$ 和 $156 \mathrm{~W} / \mathrm{cm}^{2}$, 显然 对 $488.0 \mathrm{~nm}$ 的限幅效果较好, 这也正是样品对 $488.0 \mathrm{~nm}$ 波长光的热致折射率 $\left|n_{2}\right|$ 较大的缘 故.
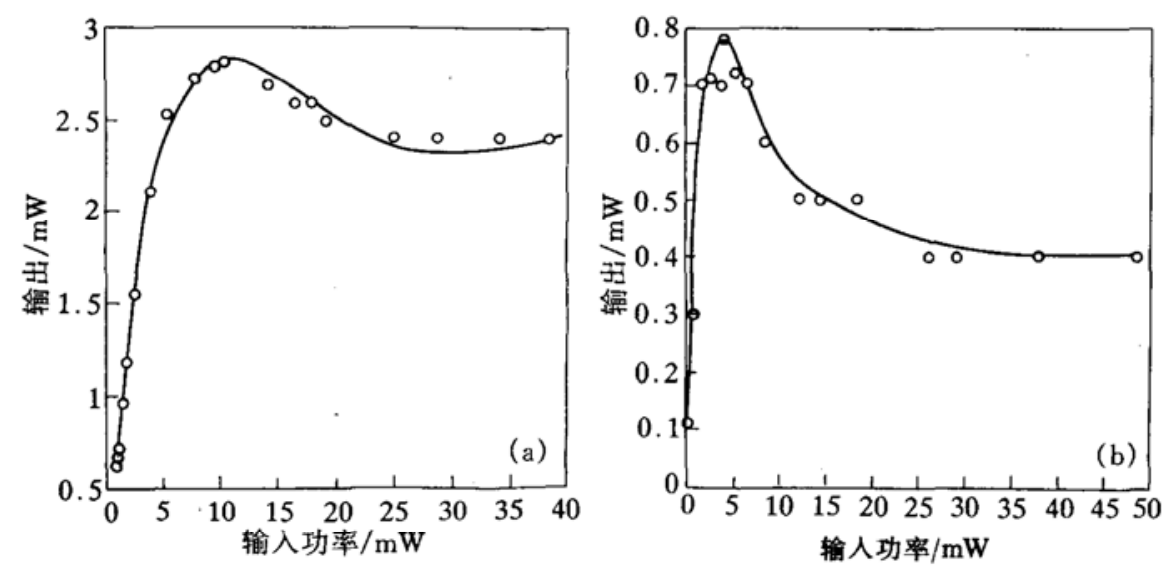

图 $3 \mathrm{SnO}_{2}$ 纳米微粒光束限制特性

(a) $\lambda=514.5 \mathrm{~nm}$, (b) $\lambda=488.0 \mathrm{~nm}$

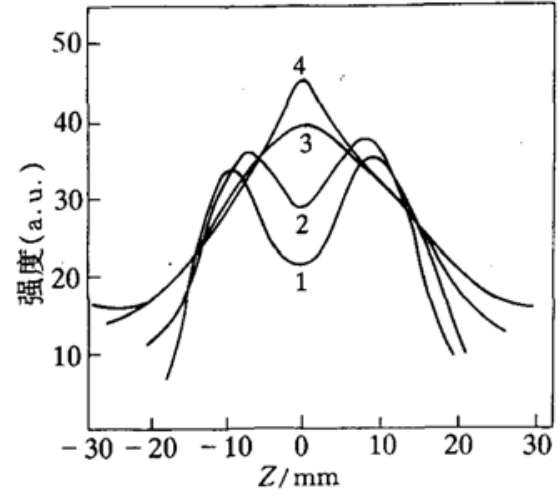

图 4 不同人射功率下透过强度曲线

1. $P_{\text {in }}=22.5 \mathrm{~mW}$, 2. $P_{\text {in }}=17.5 \mathrm{~mW}$,

3. $P_{\mathrm{in}}=9.7 \mathrm{~mW}, 4 . P_{\mathrm{in}}=8.5 \mathrm{~mW}$

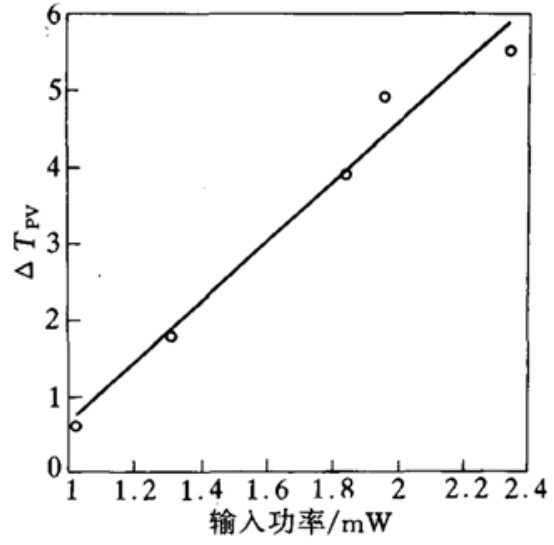

图 $5 \Delta T_{\mathrm{pv}}$ 与人射光功率的关系 $(\lambda=514.5 \mathrm{~nm})$

为了进一步探讨因负透镜效应而引起的光限幅特性, 我们又研究了样品在较高激光功率 作用下的透射特性. 将图 1 光栏移去, 直接探测样品透过光强, 结果如图 4 所示 (激光波长为 $488.0 \mathrm{~nm}$ ). 在 $Z=\theta$ 位置处曲线 3 和 4 有明显峰存在, 这是由于微粒表面大量亚稳性质的表面 
态导致饱和吸收所致. 当将人射激光功率再进一步增大时, 样品的热透镜效应增强, 透射光 束急剧散开, 致使光斑尺寸远大于会聚透镜 $L_{2}$ 的孔径 (本文中 $L_{2}$ 孔径为 $20 \mathrm{~mm}$ ), 于是在焦点 $Z=0$ 处, 样品透过光强出现明显凹陷, 如图 4 中曲线 1 和 2 所示. 因而通过选择不同尺寸光栏 孔径, 可以制成不同要求的光限幅器.

为了验证上述理论计算的正确性,我们分别测定了 $514.5 \mathrm{~nm}$ 激光在 $2.34,1.95,1.83,1.31$ 和 $1.02 \mathrm{~mW}$ 五个不同人射功率下的 $Z$-扫描归一化透过率曲线,图 5 为相应归一化透过率峰-谷差 $\Delta T_{\mathrm{pv}}$ 与人射光功率 $P_{\mathrm{in}}$ 的关系, 显然是一正比关系, 从 (1) 式知:

$$
\Delta T_{\mathrm{pv}} \alpha\left|\Delta \Phi_{0}\right| \text {. }
$$

因此图 5 中 $\Delta T_{\mathrm{pv}} \alpha P_{\mathrm{in}}$ 关系进一步证实了 (2) 式的正确性.

\section{3 结论}

本文报道了在连续 $\mathrm{Ar}^{+}$激光作用下, 具有表面修饰 $\mathrm{SnO}_{2}$ 纳米微粒光限幅特性及热致折 射率 $n_{2}$ 测量方法, 结果表明 $\mathrm{SnO}_{2}$ 纳米微粒具有较大的 $n_{2}$ 和强烈热透镜效应, 光限幅阈值低, 是一种有较大潜在应用价值的新型光限幅材料.

\section{参考文献}

1 Wang $\mathrm{Y}$, Andris S, McHugh J et al. Optical transient bleaching of quantum-onfined CdS cluster: the effect of surface-trapped electron-hole. J Chem Phys, 1990, 92(11): $6927 \sim 6939$

2 Song Q W, Zhang C P, Grross R et al. Optical limiting by chemically enhanced bacteriorhodopsion films. Optics Letters, 1993, 18(10): $775 \sim 777$

3 van Stryland E W, Vanherseele H, Woodall M A et al. Two-photon absorption, nonlinear refraction and optical limiting in semiconductors. Opt Engineering, 1985, 24(4): $613 \sim 622$

4 Sheik Bahae M, Said A A, Wei T H et al. Sensitive measurement of optical nonlinearities using a single beam. IEEE J Quantum Electron, 1990, 26(4): $760 \sim 769$

5 Sheik M, Said A A, van Stryland E W. High-sensitivity, single-beam $n_{2}$ measurements. Optics Letters, 1989, 17(17): $955 \sim 957$

6 Murcia M, Egee M, Fillard J P. Luminescence œnters in $\mathrm{SnO}_{2}$ single crystals. J Phys Chem Solids, 1974, 39: $629 \sim 635$ 